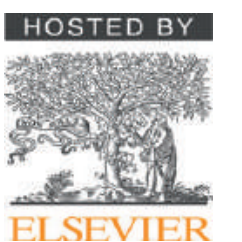

Review

\title{
The effect of knowledge about hypertension on the control of high blood pressure
}

\author{
Mahmut Kilic a , Tuğba Uzunçakmak ${ }^{\mathrm{b}}$, Huseyin Ede ${ }^{\mathrm{c}, *}$ \\ a Public Health, Bozok University, Health School, the Department of Public Health Nursing, Yozgat, Turkey \\ b Public Health Nursing, Bozok University, Health School, the Department of Public Health Nursing, Yozgat, Turkey \\ c Bozok University, the Faculty of Medicine, Department of Cardiology, Yozgat, Turkey
}

\section{A R T I C L E I N F O}

\section{Article history:}

Received 18 December 2015

Received in revised form 4 January 2016

Accepted 5 January 2016

Available online 4 March 2016

\section{Keywords:}

Hypertension

Knowledge

Primary health care

\begin{abstract}
A B S T R A C T
Objective: The aim of this study was to search the effect of knowledge about hypertension and socio-demographic characteristics on controlling high blood pressure levels among patients diagnosed with hypertension.

Methods: This is a cross-sectional study. The study population was obtained from subjects diagnosed with hypertension and applied to primary health care centers in Yozgat province center, in 2013. The subjects with informed consent were enrolled into the study $(\mathrm{n}=485)$. The data were collected via 15 -item hypertension knowledge questionnaire and personal information survey prepared in accordance with the literature. The knowledge level was classified as follows: low ( $<8$ points); moderate ( $8-11$ points); adequate ( $\geq 12$ points).

Results: Frequencies of low, moderate and high level of knowledge about hypertension were $31.3 \%, 62.1 \%$ and $6.6 \%$ respectively. The effects of other socio-demographic parameters on the knowledge level were not significant even after multivariate analysis. Knowledge level was positively related to ratio of subjects with blood pressure under control but not significant ( $\mathrm{p}>0.05)$.

Conclusion: Majority of the subjects had inadequate knowledge about hypertension, two third of the subjects did not imply significant life style modification for hypertension.

(c) 2016 The Society of Cardiovascular Academy. Production and hosting by Elsevier B.V. All rights reserved. This is an open access article under the CC BY-NC-ND license (http://creativecommons.org/licenses/by-nc-nd/4.0/).
\end{abstract}

\section{Contents}

Introduction . . . . . . . . . . . . . . . . . . . . . . . . . . . . . . . . . . . . . . . . . . . . 28

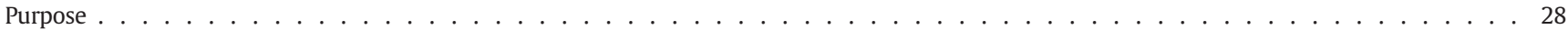

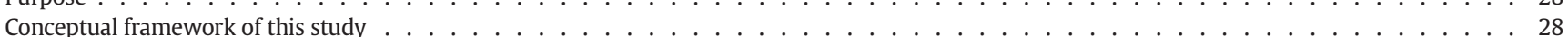

Materials and methods. . . . . . . . . . . . . . . . . . . . . . . . . . . . . . . . . . 28

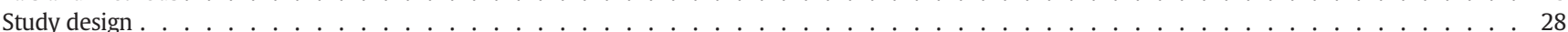

Setting and samples . . . . . . . . . . . . . . . . . . . . . . . . . . . . . . . . . . . . . . . . . . . 28

Ethical consideration . . . . . . . . . . . . . . . . . . . . . . . . . . . . . . . . . . . . . . . . . 28

Measurement . . . . . . . . . . . . . . . . . . . . . . . . . . . . . . . . . . . . . . . 28

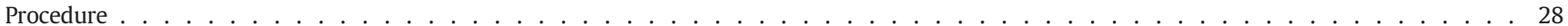

Statistical analysis . . . . . . . . . . . . . . . . . . . . . . . . . . . . . . . . . . . . . 29

Results....... 29

Discussion .. . . . . . . . . . . . . . . . . . . . . . . . . . . . . . . . . . . . 30

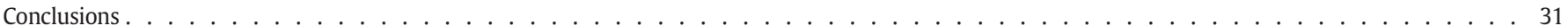

Practice implications . . . . . . . . . . . . . . . . . . . . . . . . . . . . . . . . . . . . . . . . . . . . . . . . . . . 31

Conflicts of interest ... . . . . . . . . . . . . . . . . . . . . . . . . . . . . . . . . . . . . 31

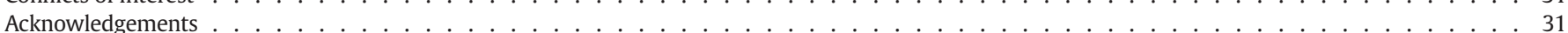

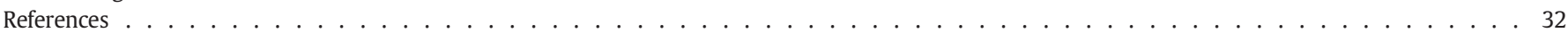

\footnotetext{
* Corresponding author. Tel.: +90505671 1104 (mobile), +90 3542127060 (office); fax: +903542123739.

E-mail addresses: mahmutkilic@yahoo.com (M. Kilic), u.cakmak@windowslive.com (T. Uzunçakmak), huseyinede@gmail.com (H. Ede).

Peer review under responsibility of The Society of Cardiovascular Academy.
} 


\section{Introduction}

High blood pressure (HBP) is a leading major risk factor for chronic diseases and deaths. The prevalence of patients with hypertension (HT) had reached from 600 million in 1980 to one billion in 2008. ${ }^{1}$ The prevalence of HBP was approximately $40 \%$ among adults of 25 years and above in 2008 . Approximately 7.5 million people $(12.8 \%$ of all-cause deaths) die every year due to HBP. ${ }^{2}$ It is estimated that HT is responsible for $45 \%$ of deaths due to heart diseases and $51 \%$ of deaths due to stroke. HBP consists of 3.7\% of Disability Adjusted Life Years (DALY). ${ }^{1}$ Even prehypertension (PreHT) increases mortality risk due to cardiovascular and stroke-related diseases. ${ }^{3}$

According to Turkey Burden of Disease Study (TBDS) 2004, the leading factor for DALY was found to be HBP among seven most frequent factors. It was estimated that the prompt control of this factor would prevent approximately one of every four (25.2\%) deaths. ${ }^{4}$ According to the data derived from Turkish Statistics Institute (TSI) 2013, 39.8\% of all deaths stem from circulation-related disorders and $12.8 \%$ of these deaths were related to HT. ${ }^{5}$ The prevalence of hypertension is $32.2 \%$ among males and $30.5 \%$ among females in developing countries while these values are $40.8 \%$ and $33.0 \%$ respectively in developed countries. ${ }^{6}$ In our country HT prevalence is found to be $35.1 \%$ according to the results of SALTurk trial held in 2008, it was $31.3 \%$ according to TURDEP II trial held in 2010 and it was 30.3\% according to Turkish Society of Hypertension and Kidney Diseases ${ }^{7}$ made PatentT2 trial held in 2012. ${ }^{7-9}$ It seems that increasing trend in HT prevalence is stopped in recent years in Turkey.

The ratio of taking BP under control among hypertensive patients is $28.7 \%$ in our country while it is $29.6 \%$ among males and $34 \%$ among females in developing countries and 33.2\% among males and $38.4 \%$ among females in developed countries respectively. ${ }^{6,7}$ Chronic Diseases and Risk Factors Survey (CDRFS) in Turkey 2011 revealed that $85 \%$ of patients with hypertension used medication and $72 \%$ of hypertensive patients under medication had blood pressure values within targeted levels. $^{10}$

The studies held in Pakistan revealed that hypertensive patients had inadequate knowledge about HT and the frequency of patients with BP under control was higher among the patients with high level of knowledge about HT. ${ }^{11,12}$ Similarly, the study held in USA also showed that hypertensive patients had the low level of knowledge about the health issues. ${ }^{13}$ In Turkish population, it was also found that the participants had the low level of knowledge about HT. ${ }^{14}$

WHO calls attention to importance of primary health care in struggle against HT and it pointed that health professionals, especially nurses, should take part in creating awareness among the society members and they should take active role in organizing educational meetings about risk factors. ${ }^{1,15}$

\section{Purpose}

The aim of this study was to search the relation between knowledge about HT, socio-demographic characteristics and obtaining controlled BP levels among patients diagnosed with HT.

\section{Conceptual framework of this study}

In this study, effects of HT knowledge level and socio-demographic factors on HT control were made by multivariate analysis that examined which variables were more important.

\section{Materials and methods}

Study design

This was a cross-sectional study aimed at identifying the knowledge about HT which impacts the controlled BP levels of patients with HT.

\section{Setting and samples}

The study population was obtained from subjects diagnosed with HT and applied to primary health care centers in Yozgat province center between January 2013 and December 2013. Random cluster sampling method was used to determine sample size. There had been 7 Family Health Centers (FHC) in the province center at the time of sampling. Of them, three FHCs $(1,3$, and 5$)$ were selected randomly for sampling. According to TSI 2012 data, ${ }^{16}$ Yozgat province center has 78,328 residents and the number of people aged above 18 years old was approximately 56,000. SaltTurk trial reported the frequency of HT prevalence among adults over 18 years old as $35 \%{ }^{8}$ Considering all these data, the expected number of people with HT above 18 years old was 19,600 people. Size of the sample was determined as follows: The estimated sampling universe (people with HT) $=19,600$; the ratio of subjects with $\mathrm{BP}$ under control $=30 \%$ (according to CDRFS results) ${ }^{10}$; deviation of this ratio $=0.05$; and the probability of a making type I error $(\alpha)=$ 0.05 . As a result, the estimated sample size was found to be 343 people. Since multivariate analyses were planned for BP levels, level of knowledge about HT and socio-demographic characteristics, it was decided to increase the number of subjects $50 \%$ more than the estimated sample size. Finally, 485 subjects were enrolled into the study.

\section{Ethical consideration}

Informed consent of each subject, ethical and official approval from the local authorities were obtained for the study accordingly and the investigation was performed in accordance with the principles outlined in the Declaration of Helsinki.

\section{Measurement}

A questionnaire was prepared by the researchers in accordance with the literature to measure the level of knowledge about HT. The questionnaire had 15 items as follows: three questions about BP classification; four questions about HT complications, four questions about treatment and BP control; and four questions about signs and followup of HT. ${ }^{17}$ And also a survey was formed to get data about sociodemographic characteristics of the subjects. Total scores for the questionnaire about HT knowledge ranged from 0 to 15 at maximum. The subjects were classified further in respect to the scores obtained from the questionnaire as follows: low level of knowledge $<8$ points; moderate level of knowledge 8 to 11 points; and adequate level of knowledge $\geq 12$ points. $^{17}$

\section{Procedure}

The questionnaire and survey were fulfilled by the subjects under the observation of an independently trained interviewer. Height and weight of all subjects were measured with automatic digital scale at morning times between 08:00 to 11:00 o'clock under casual clothes without shoes. The blood pressure (BP) levels were measured from the right and left arms of the subjects in a sitting position by one trained observer blind to the study at the place of interview. BP was measured twice with 10 min interval. The systolic BP (SBP) and diastolic BP (DBP) were recorded at the first and fifth Korotkoff phases respectively using a mercury sphygmomanometer. The average of the four BP measurements was used for analysis. BP levels were classified in accordance with Joint National Committee Report-7 as follows: normal: SBP $<120 \mathrm{mmHg}$ and DBP < $80 \mathrm{mmHg}$; PreHT: SBP 120-139 mmHg and/or DBP $80-89 \mathrm{mmHg}$; HT: $\geq 140 \mathrm{mmHg}$ and/or $\geq 90 \mathrm{mmHg} .{ }^{18}$ The Joint National Committee Report-8 recommend, in the general population aged 60 years or older, initiate pharmacologic treatment to lower BP at SBP of $150 \mathrm{mmHg}$ or higher or DBP of $90 \mathrm{mmHg}$ or higher and treat to a goal SBP lower than $150 \mathrm{mmHg}$ and goal DBP lower than $90 \mathrm{mmHg} .{ }^{19}$ The subjects who have BP measurement of SBP $<140 \mathrm{mmHg}$ ( $\geq 60$ age, 
$\mathrm{SBP}<150 \mathrm{mmHg}$ ) and/or DBP $<90 \mathrm{mmHg}$ at the time of interview were classified as subjects with BP under control. ${ }^{20}$ Body Mass Index (BMI) was calculated by the formula (BMI = weight in $\mathrm{kg} /(\text { height in } \mathrm{m})^{2}$ ) defined according to the WHO criteria. ${ }^{21}$ Patients were classified as normal weight (BMI $18.5-24.9 \mathrm{~kg} / \mathrm{m}^{2}$ ), overweight (BMI $25.0-29.9 \mathrm{~kg} / \mathrm{m}^{2}$ ), obese class I (BMI $30.0-34.9 \mathrm{~kg} / \mathrm{m}^{2}$ ), obese class II (BMI $35.0-39.9 \mathrm{~kg} / \mathrm{m}^{2}$ ) or obese class III $\left(\right.$ BMI $40 \mathrm{~kg} / \mathrm{m}^{2}$ or more).

\section{Statistical analysis}

The data were analyzed with SPSS package program. Statistical analyses were carried out by the help of simple correlation tests and backward LR model of multiple variables binary logistic regression (BLR). ${ }^{22}$ In the BLR analysis, the state of being under the control of BP (coded; controlled: 1, uncontrolled: 0) was used as the dependent variable. The independent variables; HT knowledge score, age, BMI, and disease duration as a continuous variable, education level, perception of income level, and level of satisfaction in life as an ordinal variable, gender, marital status and employment status were included in the model as a categorical variable. Continuous variables were expressed in mean $\pm S D$, categorical variables were shown in percentage, $p$-values of $<0.05$ was used to show statistical significance.

\section{Results}

The study included 485 subjects. $57.7 \%$ of the subjects were female and $85.5 \%$ of study population were aged 50 years old and above with a range of 18 to 90 years old. Median age was 63 years old with the average age of $61.5 \pm 10.9$ years. $83.5 \%$ of the study population were married, $28.2 \%$ of them had education duration of 5 years or less, however prevalence of subjects graduated from secondary school or above was $12.8 \% .10 .1 \%$ of the subjects were employed. $75.1 \%$ of them claimed that they satisfied with quality of their life. $26 \%$ of the study population reported that their economic status were well enough while $6.4 \%$ of them claimed that they had low economical status (Tables 1,2).

It was found that $36.5 \%$ of the subjects with HT consumed enough fruit/vegetables ( $\geq 3$ times a day), $31.3 \%$ of them exercised sufficiently (at least 3 days and 150 min per week) while $52.0 \%$ of the study population did not exercise at all. $25.6 \%$ of all hypertensive subjects generally did not consume salt while $34.4 \%$ of them claimed usage of low level salt on their diet. $10.5 \%$ of hypertensive subjects were a current smoker (Table 3), 65.2\% of the study population had one of the concurrent comorbidities (such $6.7 \%$ with diabetes). Ratio of parental HT was $47.4 \%$ (Table 2).

According to results of the questionnaires, we found that frequencies of poor, moderate, and adequate level of knowledge about HT among subjects with HT were $31.3 \%, 62.1 \%$, and $6.6 \%$ respectively. Level of knowledge was correlated significantly with educational status but not with other variables (Table 1). Among the study population, BP value and HT duration did not show any statistical correlation between score of the HT knowledge. Also, the knowledge score mean of the subjects did not significantly differ in respect to gender, marital status, and economic status however HT knowledge scores mean was statistically different with age clusters and educational status (Table 1). HT knowledge score of old subjects aged 70 years and above had significantly lower than other age groups' scores (posthoc LSD, $\mathrm{p}<0.05$ ). Other age clusters didn't differ in respect to each other $(p>0.05)$. Average knowledge score of subjects without formal education had significantly lower than that of subjects with primary school and above graduate (posthoc Tamhane, $\mathrm{p}<0.05$ ) while other educational states did not show any significant difference in respect to each other $(\mathrm{p}>0.05)$. In multivariate regression analyses, considering age (in year) and educational states (in ordinal value) as independent variables, the contribution of educational states on HT knowledge score was statistically significant ( $B=0.408$, $\mathrm{p}<0.001$ ) while contribution of age did not significantly contribute to
Table 1

Hypertension knowledge distribution according to socio-demographic properties in the study population.

\begin{tabular}{|c|c|c|c|c|c|}
\hline \multirow{2}{*}{$\frac{\text { Risk factors }}{\text { Gender }}$} & \multicolumn{5}{|c|}{ HT knowledge level a } \\
\hline & $\mathrm{n}(\%)^{\mathrm{b}}$ & $\mathrm{X} \pm \mathrm{SD}$ & Poor n (\%) & $\begin{array}{l}\text { Moderate } \\
\mathrm{n}(\%)\end{array}$ & $\begin{array}{l}\text { Adequate } \\
\mathrm{n}(\%)\end{array}$ \\
\hline Male & $205(42.3)$ & $8.5 \pm 2.1$ & $59(28.8)$ & $133(64.9)$ & $13(6.3)$ \\
\hline Female & $280(57.7)$ & $8.3 \pm 2.4$ & $93(33.2)$ & $168(60.0)$ & $19(6.8)$ \\
\hline Age groups & \multicolumn{3}{|c|}{$\mathrm{t}=1.24, \mathrm{p}=0.22$} & \multicolumn{2}{|c|}{$X^{2}=1.23, P=0.540$} \\
\hline$<50$ & $69(14.2)$ & $8.7 \pm 2.1$ & $22(31.9)$ & $41(59.4)$ & $6(8.7)$ \\
\hline $50-59$ & $124(25.6)$ & $8.5 \pm 2.0$ & $39(31.5)$ & $76(61.3)$ & $9(7.3)$ \\
\hline $60-69$ & $177(36.5)$ & $8.5 \pm 2.3$ & $48(27.1)$ & $120(67.8)$ & $9(5.1)$ \\
\hline$\geq 70$ & $115(23.7)$ & $7.8 \pm 2.5$ & $43(37.4)$ & $64(55.7)$ & $8(7.0)$ \\
\hline Education & \multicolumn{3}{|c|}{$\mathrm{F}=3.42, \mathrm{p}=0.02$} & \multicolumn{2}{|c|}{$X^{2}=5.33, P=0.503$} \\
\hline Illiterate & $137(28.2)$ & $7.6 \pm 2.6$ & $58(42.3)$ & 75 (54.7) & $4(2.9)$ \\
\hline Primary school & $234(48.2)$ & $8.6 \pm 2.1$ & $69(29.5)$ & $150(64.1)$ & $15(6.4)$ \\
\hline Secondary school & $52(10.7)$ & $8.8 \pm 2.0$ & $12(23.1)$ & $36(69.2)$ & $4(7.7)$ \\
\hline High school or more & $62(12.8)$ & $9.1 \pm 1.8$ & $13(21.0)$ & $40(64.5)$ & $9(14.5)$ \\
\hline Marital status & \multicolumn{3}{|c|}{$\mathrm{F}=8.7, \mathrm{p}<0.001$} & \multicolumn{2}{|c|}{$X^{2}=19.44, P=0.003$} \\
\hline Married & $405(83.5)$ & $8.5 \pm 2.2$ & $121(29.9)$ & $255(63)$ & $29(7.2)$ \\
\hline Not married & $80(16.5)$ & $8.0 \pm 2.5$ & $31(38.8)$ & $46(57.5)$ & $3(3.8)$ \\
\hline Economic level & \multicolumn{3}{|c|}{$t=1.73, p=0.085$} & \multicolumn{2}{|c|}{$X^{2}=3.18, P=0.204$} \\
\hline High & $126(26.0)$ & $8.5 \pm 2.1$ & & $33(26.2)$ & $10(7.9)$ \\
\hline Middle & $328(67.6)$ & $8.4 \pm 2.3$ & $107(32.6)$ & $200(61.0)$ & $21(6.4)$ \\
\hline Low & $31(6.4)$ & $7.8 \pm 2.8$ & $12(38.7)$ & $18(58.1)$ & $1(3.2)$ \\
\hline Current BP level & \multicolumn{3}{|c|}{$\mathrm{F}=1.1, \mathrm{p}=0.341$} & \multicolumn{2}{|c|}{$X^{2}=3.11, P=0.540$} \\
\hline Normal & $105(21.6)$ & $8.3 \pm 2.4$ & $35(33.3)$ & 65 (61.9) & $5(4.8)$ \\
\hline PreHT & $224(46.2)$ & $8.5 \pm 2.2$ & $61(27.2)$ & $144(64.3)$ & $19(8.5)$ \\
\hline HT & $156(32.2)$ & $8.2 \pm 2.3$ & $56(35.9)$ & $92(59.0)$ & $8(5.1)$ \\
\hline HT duration & \multicolumn{3}{|c|}{$\mathrm{F}=1.2, \mathrm{p}=0.292$} & \multicolumn{2}{|c|}{$X^{2}=8.48, P=0.076$} \\
\hline$<5$ years & $157(32.4)$ & $8.5 \pm 2.1$ & $49(31.2)$ & $96(61.1)$ & $12(7.6)$ \\
\hline 5-9 years & $120(24.7)$ & $8.3 \pm 2.5$ & $36(30.0)$ & $76(63.3)$ & $8(6.7)$ \\
\hline $10-14$ years & $98(20.2)$ & $8.5 \pm 2.1$ & $29(29.6)$ & $63(64.3)$ & $6(6.1)$ \\
\hline$\geq 15$ years & $110(22.7)$ & $8.1 \pm 2.4$ & $38(34.5)$ & $66(60.0)$ & $6(5.5)$ \\
\hline & \multicolumn{3}{|c|}{$\mathrm{F}=0.8, \mathrm{p}=502$} & \multicolumn{2}{|c|}{$X^{2}=1.24, P=0.975$} \\
\hline Total & $485(100.0)$ & $8.4 \pm 2.3$ & $152(31.3)$ & $301(62.1)$ & $32(6.6)$ \\
\hline
\end{tabular}

${ }^{\mathrm{a}} \mathrm{HT}$ knowledge score $<8$ is poor, $8-11$ is moderate, $\geq 12$ is adequate. ${ }^{\mathrm{b}}$ Percentages are sum of columns t: Independent Student t test, F: One way ANOVA.

HT knowledge score $(\mathrm{B}=-0.013, \mathrm{p}=0.167)$. Educational status contributed only $4.5 \%$ of changes in HT knowledge score $\left(R^{2}=0.045\right)$.

Only some of subjects knew that HBP does not show sign (7.4-30.7\%) and HT does not lead any cancer (23.5\%). When asked about the definition of normal BP, preHT and HT, respectively $65.2 \%, 49.7 \%$ and $72 \%$ of the subjects answered the relevant BP classification correctly. Most of the subjects knew HBP lowering methods correctly (71.3-80.6\%) and the necessity of regular intake of antihypertensive drugs (95.7\%).

According to blood pressure measurement results of the subjects, $21.6 \%$ of the subjects had normal BP, $46.2 \%$ with preHT and $32.2 \%$ with hypertensive level of BP. BP level of the subjects did not reveal any significant relation to age, gender, educational, marital, employment and economic states ( $p>0.05$ for all comparisons). Although subjects with hypertensive level of BP measurement had lower knowledge score compared to normal and preHT levels it did not reach the level of statistical significance $(p>0.05)$. Subjects with higher BMI value had significantly higher frequency of having hypertensive BP level $(\mathrm{p}<0.05)$. $25.5 \%$ of subjects with BMI less than $25 \mathrm{~kg} / \mathrm{m}^{2}$ and $35.5 \%$ of subjects with BMI $30 \mathrm{~kg} / \mathrm{m}^{2}$ and more had hypertensive level of BP measurement (Table 2). The case of classifying the subjects into hypertensive BP measurement and the others, BMI values did not show significant difference between the groups $\left(X^{2}=2.64, p=0.267\right)$.

It was found that HT duration of the subjects was less than 5 years in $32.4 \%$ of the subjects and $\geq 15$ years in $22.7 \%$ of the subjects. Subjects with HT duration of less than 5 years had significantly higher frequency of hypertensive BP measurement compared to subjects with HT duration of $\geq 15$ years ( $35.0 \%$ vs. $30.9 \%$ respectively, $\mathrm{p}<0.05$ ). 
Table 2

Blood pressure levels distribution according to socio-demographic properties in the study population.

\begin{tabular}{|c|c|c|c|c|}
\hline \multirow[t]{2}{*}{ Characteristics } & \multicolumn{4}{|c|}{ Current blood pressure level } \\
\hline & Normal & PreHT & HT & Total \\
\hline Gender & $\mathrm{n}(\%)^{\mathrm{a}}$ & $\mathrm{n}(\%)^{\mathrm{a}}$ & $\mathrm{n}(\%)^{\mathrm{a}}$ & $\mathrm{n}(\%)^{\mathrm{b}}$ \\
\hline Male & $47(22.9)$ & $94(45.9)$ & $64(31.2)$ & $205(42.3)$ \\
\hline Female & $58(20.7)$ & $130(46.4)$ & $92(32.9)$ & $280(57.7)$ \\
\hline Age groups (year) & \multicolumn{4}{|c|}{$\mathbf{X}^{\mathbf{2}}=0.37 \mathrm{P}=0.829$} \\
\hline$<50$ & 15 (21.7) & $35(50.7)$ & $19(27.5)$ & $69(14.2)$ \\
\hline $50-59$ & $24(19.4)$ & $49(39.5)$ & $51(41.1)$ & $124(25.6)$ \\
\hline $60-69$ & $42(23.7)$ & $87(49.2)$ & $48(27.1)$ & $177(36.5)$ \\
\hline$\geq 70$ & $24(20.9)$ & $53(46.1)$ & $38(33.0)$ & $115(23.7)$ \\
\hline Education & \multicolumn{4}{|c|}{$\mathrm{X}^{2}=7.51 \mathrm{P}=0.276$} \\
\hline Illiterate & $26(19.0)$ & $69(50.4)$ & $42(30.7)$ & $137(28.2)$ \\
\hline Primary school & $56(23.9)$ & $97(41.5)$ & $81(34.6)$ & $234(48.2)$ \\
\hline Secondary school & $11(21.2)$ & $24(46.2)$ & $17(32.7)$ & $52(10.7)$ \\
\hline High school or more & $12(19.4)$ & $34(54.8)$ & $16(25.8)$ & $62(12.8)$ \\
\hline Marital status & \multicolumn{4}{|c|}{$\mathrm{X}^{2}=5.15 \mathrm{P}=0.525$} \\
\hline Married & $86(21.2)$ & $187(46.2)$ & $132(32.6)$ & $405(83.5)$ \\
\hline Not married & $19(23.8)$ & $37(46.3)$ & $24(30.0)$ & $80(16.5)$ \\
\hline Parental HT & \multicolumn{4}{|c|}{$\mathrm{X}^{2}=0.34 \mathrm{P}=0.846$} \\
\hline Have not & $60(23.5)$ & $120(47.1)$ & $75(29.4)$ & $255(52.6)$ \\
\hline Have & $45(19.6)$ & $104(45.2)$ & $81(35.2)$ & $230(47.4)$ \\
\hline $\operatorname{BMI}\left(\mathrm{kg} / \mathrm{m}^{2}\right)$ & \multicolumn{4}{|c|}{$\mathrm{X}^{2}=2.23 \mathrm{P}=0.327$} \\
\hline$<25$ & $21(41.2)$ & $17(33.3)$ & $13(25.5)$ & $51(10.5)$ \\
\hline $25-29.9$ & $45(22.5)$ & $95(47.5)$ & $60(30.0)$ & $200(41.2)$ \\
\hline$\geq 30$ & $39(16.7)$ & $112(47.9)$ & $83(35.5)$ & $234(48.2)$ \\
\hline Economic level & \multicolumn{4}{|c|}{$\mathrm{X}^{2}=15.57 \mathrm{P}=0.004$} \\
\hline High & $27(21.4)$ & $60(47.6)$ & $39(31.0)$ & $126(26.0)$ \\
\hline Middle & $70(21.3)$ & $157(47.9)$ & $101(30.8)$ & $328(67.6)$ \\
\hline Low & $8(25.8)$ & $7(22.6)$ & $16(51.6)$ & $31(6.4)$ \\
\hline HT knowledge level & \multicolumn{4}{|c|}{$X^{2}=8.16 p=0.068$} \\
\hline Poor $(<8)$ & $35(23.0)$ & $61(40.1)$ & $56(36.8)$ & $152(31.3)$ \\
\hline Moderate (8-11) & $65(21.6)$ & $144(47.8)$ & $92(30.6)$ & $301(62.1)$ \\
\hline \multirow[t]{2}{*}{ Adequate $(\geq 12)$} & $5(15.6)$ & $19(59.4)$ & $8(25.0)$ & $32(6.6)$ \\
\hline & & $X^{2}=5.04$ & $\mathrm{p}=0.283$ & \\
\hline Total & $105(21.6)$ & $224(46.2)$ & $156(32.2)$ & $485(100.0)$ \\
\hline
\end{tabular}

${ }^{\mathrm{a}}$ Percentages are sum of rows, ${ }^{\mathrm{b}}$ percentages are sum of columns.

The subjects were questioned about their BP levels according to their experience, $67.2 \%$ of the subjects answered that they had a normal level of BPs while $26 \%$ of them had HBP levels. However, the BP measurement results of the subjects who claimed normal BP during their lifetime revealed that only $25.8 \%$ of them had normal BP in reality while $24.2 \%$ of them had hypertensive BP measurement. Oppositely, BP measurement results of the subjects who claimed HBP during their lifetime revealed that only $57.1 \%$ of them had hypertensive BP in reality.

Substantial number of the subjects (84.5\%) reported regular intake of antihypertensive medication, $10.3 \%$ of the subjects claimed drug intake in case of high BP measurement, $5.2 \%$ of the subjects did not take their prescribed medication at all. Measured BP levels of subjects with regular intake of drugs were normal in $22.9 \%$ of subjects and hypertensive in $31.2 \%$ of the subjects. These rates were $14.7 \%$ and $37.3 \%$ respectively among subjects who did not take their medication or take irregularly (Table 3).

In the study, $40.2 \%$ of the subjects reported the usage of alternative methods to control BP, $4.5 \%$ of the subjects reported regular jogging, and $2.7 \%$ of the subjects reported diet modification. $52.6 \%$ of the subjects claimed that they use only the prescribed drugs to control BP. $34.1 \%$ of only drug users had hypertensive BP measurements while $29.2 \%$ of alternative method users had hypertensive BP measurements (Table 3 ). This ratio was $22.7 \%$ among the subjects performing regular jogging. $35.7 \%$ of the study population noted that they got an education about HT (Table 3 ). $28 \%$ of all subjects ( $78.4 \%$ of educated subjects) got this education from medical doctors, $4.3 \%$ of nurses and $3.3 \%$ of both medical
Table 3

Blood pressure levels of the subjects with hypertension according to the factors affecting blood pressure levels.

\begin{tabular}{|c|c|c|c|c|}
\hline \multirow[t]{2}{*}{ Characteristics } & \multicolumn{4}{|c|}{ Current blood pressure level } \\
\hline & Normal & PreHT & HT & Total \\
\hline HT medication & $\mathrm{n}(\%)^{\mathrm{a}}$ & $\mathrm{n}(\%)^{\mathrm{a}}$ & $\mathrm{n}(\%)^{\mathrm{a}}$ & $\mathrm{n}(\%)^{\mathrm{b}}$ \\
\hline Using regular & $94(22.9)$ & $188(45.9)$ & $128(31.2)$ & $410(84.5)$ \\
\hline Using irregular & $11(14.7)$ & $36(48.0)$ & $28(37.3)$ & $75(15.5)$ \\
\hline HT training & \multicolumn{4}{|c|}{$\mathrm{X}^{2}=2.80 \mathrm{P}=0.247$} \\
\hline Not received & $73(23.4)$ & $140(44.9)$ & 99 (31.7) & $312(64.3)$ \\
\hline Received & $32(18.5)$ & $84(48.6)$ & $57(32.9)$ & $173(35.7)$ \\
\hline $\begin{array}{l}\text { Alternative or complementary } \\
\text { medicine }\end{array}$ & \multicolumn{4}{|c|}{$\mathrm{X}^{2}=1.61 \mathrm{P}=0.447$} \\
\hline Not admitted & $65(22.4)$ & $126(43.4)$ & $99(34.1)$ & $290(59.8)$ \\
\hline Admitted & $40(20.5)$ & $98(50.3)$ & $57(29.2)$ & $195(40.2)$ \\
\hline Exercise level & \multicolumn{4}{|c|}{$\mathrm{X}^{2}=2.24 \mathrm{P}=0.327$} \\
\hline Not exercising & $52(20.6)$ & $116(46.0)$ & $84(33.3)$ & $252(52.0)$ \\
\hline Inadequate & $17(21.0)$ & $40(49.4)$ & $24(29.6)$ & $81(16.7)$ \\
\hline Adequate & $36(23.7)$ & $68(44.7)$ & $48(31.6)$ & $152(31.3)$ \\
\hline $\begin{array}{l}\text { Fruit and vegetable } \\
\text { consumption }\end{array}$ & \multicolumn{4}{|c|}{$X^{2}=0.96 P=0.916$} \\
\hline Not eat every day & $23(20.4)$ & $51(45.1)$ & $39(34.5)$ & $113(23.3)$ \\
\hline One meal per day & $19(18.1)$ & $55(52.4)$ & $31(29.5)$ & 105 (21.6) \\
\hline Two meals per day & $17(18.9)$ & 35 (38.9) & $38(42.2)$ & 90 (18.6) \\
\hline$\geq 3$ meals per day & $46(26.0)$ & $83(46.9)$ & $48(27.1)$ & $177(36.5)$ \\
\hline Salt consumption habits & \multicolumn{4}{|c|}{$X^{2}=9.17 P=0.164$} \\
\hline Normal/more salty & $47(24.2)$ & $84(43.3)$ & $63(32.5)$ & $194(40.0)$ \\
\hline Less salty & $33(19.8)$ & $81(48.5)$ & $53(31.7)$ & $167(34.4)$ \\
\hline Salt less & $25(20.2)$ & $59(47.6)$ & $40(32.3)$ & $124(25.6)$ \\
\hline How to continue BP & \multicolumn{4}{|c|}{$\mathrm{X}_{2}=1.61 \mathrm{p}=0.807$} \\
\hline Normal & $84(25.8)$ & $163(50.0)$ & $79(24.2)$ & $326(67.2)$ \\
\hline High & $11(8.7)$ & $43(34.1)$ & $72(57.1)$ & $126(26.0)$ \\
\hline Unstable & $10(30.3)$ & $18(54.5)$ & $5(15.2)$ & $33(6.8)$ \\
\hline HT duration & \multicolumn{4}{|c|}{$\mathrm{X}_{2}=52.69 \mathrm{P}<0.001$} \\
\hline$<5$ years & $33(21.0)$ & 69 (43.9) & $55(35.0)$ & $157(32.4)$ \\
\hline $5-9$ years & $38(31.7)$ & $47(39.2)$ & $35(29.2)$ & $120(24.7)$ \\
\hline $10-14$ years & $20(20.4)$ & $46(46.9)$ & $32(32.7)$ & $98(20.2)$ \\
\hline$\geq 15$ years & $14(12.7)$ & $62(56.4)$ & $34(30.9)$ & $110(22.7)$ \\
\hline & \multicolumn{4}{|c|}{$\mathrm{X}_{2}=14.43 \mathrm{p}=0.025$} \\
\hline Total & $105(21.6)$ & $224(46.2)$ & $156(32.2)$ & $485(100.0)$ \\
\hline
\end{tabular}

a Percentages are sum of rows, ${ }^{\mathrm{b}}$ percentages are sum of columns.

doctors and nurses. $18.6 \%$ of educated subjects reported that they got this education once, $5.6 \%$ of them twice, $6.8 \%$ of them three times, and $4.7 \%$ of them four or more times during their lifetime. There was not any significant relation between education about HT and degree of BP levels measured at the time of interview (Table 3 ).

Since age vs. BMI $(\mathrm{r}=-0.146, \mathrm{p}<0.001)$, age vs disease duration $(\mathrm{r}=0.301, \mathrm{p}<0.001)$ and age vs. educational status (Spearman's rho $=-0.304, \mathrm{p}<0.001$ ) had significant correlation, these parameters were included in the analyses. Among the factors affecting BP level statistically with the $\mathrm{p}$-value $<0.10$, significant independent variables as BMI, HT duration and use of alternative method and not significant independent variables as age, educational status and knowledge level about HT were all included in multivariate BLR analyses. HT knowledge score, gender, age, BMI, disease duration, education level, and perception of income level as independent variables were included in the BLR analyses. All independent variables did not show statistical significance, thus relevant table showing the results of this analyses were not expressed further in another table.

\section{Discussion}

In this study, the relation between knowledge about HT, sociodemographic characteristics and obtaining controlled BP levels were evaluated among patients diagnosed with HT with the help of 
multivariate analyses. As known, increased knowledge about the disease promotes the compliance of the patient with prescribed medications. However, there have been few studies searching the relation between awareness, knowledge and real-time BP measurements in Turkish population. Thus, we designed this study to evaluate the socio-demographic factors affecting outcomes of hypertensive patients.

We found that approximately one-third of patients with HT had a poor level of knowledge about HT and very few numbers of patients (6.6\%) had adequate level knowledge (Table 1). In USA, the frequency of HT patient with the poor level knowledge about HT was $22 \% .{ }^{23}$ In same study, $86 \%$ of the subjects defined BP categories properly, that value was $72.4 \%$ in our study. In Pakistan, only $0.8 \%$ of hypertensive patients claimed that they had adequate knowledge about HT. ${ }^{11}$ All these data indicates that patients in developed countries have more knowledge about HT compared to people in underdeveloped or developing countries. It means that there may be a correlation between industrialization level and awareness for HT.

The ratio of subjects with BP under control was $75 \%$ among subjects with adequate level of HT knowledge and this was higher compared to the ones with moderate (69.4\%) and poor levels (63.2\%). But it was not statistically significant (Table 2). The study from Pakistan also revealed similar results. Average knowledge score of subjects with BP under control was found to be higher compared to that of subjects with uncontrolled BP (21.8 vs. 18.7 with $\mathrm{p}>0.05$ ) as found in our study. ${ }^{12}$

Educational status and level of knowledge about HT were shown to promote positively the control of HBP, but the additional effects of these factors were found to be minimal. ${ }^{24}$ Similarly, Xu LJ, Meng $Q^{25}$ found that educating patients about HT enabled reduction in SBP of $19.03 \mathrm{mmHg}$ and DBP of $10.33 \mathrm{mmHg}$. However, in our study, these variables were not significant (Table 1 ).

Another important issue in management of HT is to know asymptomatic nature of having HBP. In our study, most of the subjects (63.3-92.6\%) did not know that HBP can course without any sign and symptoms. It was $67.3 \%$ for Turkish population living around İzmir while it was $20.6 \%$ in USA. ${ }^{14,23}$ The patients assumed that they experienced headache (92.6\%) and dizziness (82.9\%) in case of HBP. Due to these false perceptions, the patients think their BP levels are under control in the absence of these complaints whereas HBP usually does not give any sign and symptoms. This false understanding adversely affects the HT control. The knowledge about HT is very important for patients to evaluate themselves-their BP measurements at home and to comply with their treatment and they can easily be aware of their general status and take precaution promptly.

In our study, we found that level of knowledge about HT increased proportionally with higher degree of educational states. However, the effect of age on the HT knowledge was not statistically significant. Thus, educational status contributed only $4.5 \%\left(R^{2}=0.045\right)$ of changes in HT knowledge score. In a study from USA, it was also shown that medical knowledge level increased proportionally with increment in degree of education and decrement in age and educational contributed $17.7 \%$ of changes in medical knowledge while age variable affected less $(6.1 \%) .{ }^{13}$ This conflicting result can be due to the different effects of educational status on the medical knowledge of the countries with different level of industrialization. Another reason for this kind of result is the difficulty in standardization of education and medical knowledge.

Most of the patients (84.5\%) reported regular intake of prescribed drugs (Table 3 ). In other studies, the ratio of regular drug intake was ranging between from $78.8 \%$ to $98.1 \% .{ }^{14,26}$ In CDRFS, it was $85 \% .{ }^{10}$ Thus, our finding was inconsistent with the literature. Among subjects taking their antihypertensive medicine promptly, two third (68.8\%) had BP level under control. This ratio differs in different studies ranging from $53.9 \%$ to $72 \%{ }^{7,10,27}$ In a hospital-based study, $78 \%$ of regular drug users had BP under control. ${ }^{28}$ All these different results imply that there are different rates of controlling BP in spite of regular intake of prescribed medications. The reason for such result may be due to different sampling universe and varied frequency of planned admissions for the diseasesince regularity of outpatient admissions can change the course of treatment and use of prescribed medications.

Age, educational status, HT knowledge score, BMI, HT duration and use of alternative or complementary medicine methods were not found to be significant in controlling BP among hypertensive patients after performing multivariate FLR analyses. $40.2 \%$ of the subjects reported the use of alternative medicine method to control BP. HT control rate was $70.8 \%$ among alternative method users and $65.9 \%$ among subjects who do not use any alternative method, but the difference was not statistically significant. Still this difference can be explained in a way that patients using alternative medicine methods were more motivated to control their BP compared to the others. In the study from İzmir, salt restriction, diet, weight loss, quitting smoking, exercise and alcohol restriction were found to promote positively the treatment of HT. ${ }^{14}$ Our study results revealed that the subjects' knowledge to keep BP under control was moderate, but they did not apply promptly what they knew.

Approximately one-third of the study population noted that they got education about HT (Table 3). Most of the educated subjects (78.4\%) got this education from medical doctors, $4.3 \%$ of them from nurses and $3.3 \%$ of them from both medical doctors and nurses. Oskay, Onsuz ${ }^{14}$ also described the source of knowledge as mostly doctors, then social environment, television and newspapers in order. Nurses can be a source of knowledge about HT and are expected to the important role in educating subjects in future.

There are some limitations to our study. Firstly, the study population consisted of residents in Yozgat province, thus the results may not be extrapolated to general population of Turkey. Secondly, the study enrolled only subjects from primary health centers, thus the data in hand can't reflect hypertensive subjects applied to secondary or tertiary health centers. Thirdly, this is a cross-sectional study based on claims of subjects, thus the answers of subjects may be biased.

\section{Conclusions}

Increase in number of deaths due to cardiovascular diseases in recent years diverted researchers' attention to prevention and controlling of HBP which is a leading cause of cardiovascular diseases. According to the results of our study, (1) there was no relationship between HT knowledge level and controlling high blood pressure, (2) majority of subjects did not have sufficient knowledge about HT, and (3) two third of the subjects did not perform important lifestyle modifications to control BP.

\section{Practice implications}

Nurses should follow patients with HT, should replace lack of knowledge, promote behavioral changes, and should be motivated to prepare educational programs for the patients.

\section{Conflicts of interest}

We wish to confirm that there are no known conflicts of interest associated with this publication and there has been no significant financial support for this work that could have influenced its outcome.

\section{Acknowledgements}

This research was not supported by any material and financial resource.

Ethical and official approvals from the local authorities were obtained for the study accordingly and the investigation was performed in accordance with the principles outlined in the Declaration of Helsinki. 


\section{References}

1. WHO. A Global Brief on Hypertension: Silent Killer, Global Public Health Crisis Genava: World Health Organization; 2013.

2. A. Alwan. Global Status Report on Noncommunicable Diseases 2010. World Health Organization; 2011.

3. Huang Y, Su L, Cai X, et al. Association of all-cause and cardiovascular mortality with prehypertension: a meta-analysis. Am Heart J 2014;167:160-168 [e1].

4. Turkey Health Ministry. Turkey Burden of Disease Study (TBDS) 2004. Ankara: Aydoğdu Ofset Matbaacılık San. ve Tic. Ltd. Sti.; 2007.

5. TSI. Causes of Death Statistics. Ankara: Turkish Statistical Institute (TSI); 2013;2014

6. Pereira M, Lunet N, Azevedo A, Barros H. Differences in prevalence, awareness, treatment and control of hypertension between developing and developed countries. J Hypertens 2009;27:963-975.

7. TSHKD. Turkish hypertension prevalence study 2012 (PatenT2). Turkish Society of Hypertension and Kidney Diseases (TSHKD); 2012.

8. Erdem Y, Arici M, Altun B, et al. The relationship between hypertension and salt intake in Turkish population: SALTURK study. Blood Press 2010;19:313-318.

9. Satman I, TURDEP-II SG. Turkey Diabetes Prevalence Studies: TURDEP-I and TURDEP-II. 47 National Congress of Diabetes. Antalya, Turkey: Rixos Sungate Hotel 2011.

10. Ünal B, Ergör G, Dinç-Horasan G, Kalaça S, Sözmen K. Chronic Diseases and Risk Factors Survey in Turkey. Ankara: Anıl Matbaa Ltd. Şti; 2013.

11. Saleem F, Hassali M, Shafie A, Awad A, Bashir S. Association between knowledge and drug adherence in patients with hypertension in Quetta, Pakistan. Trop J Pharm Res $2011 ; 10$.

12. Almas A, Godil SS, Lalani S, Samani ZA, Khan AH. Good knowledge about hypertension is linked to better control of hypertension; a multicentre cross sectional study in Karachi, Pakistan. BMC Res. Notes 2012;5:579.

13. Levinthal BR, Morrow DG, Tu W, Wu J, Murray MD. Cognition and health literacy in patients with hypertension. J Gen Intern Med 2008;23:1172-1176.

14. Oskay EM, Onsuz M, Topuzoglu A. Assesment of hypertension knowledge, attitude and throught of policyclinic patients at a primary health care center in Izmir. $J$ Adnan Menderes Univ Med Fac 2010;11:3-9.

15. Hong W-HS. Evidence-based nursing practice for health promotion in adults with hypertension: a literature review. Asian Nurs Res 2010;4:227-245.
16. TSI. Address Based Population Registration System (ABPRS) Results. Population of localities: Turkish Statistical Instıtute; 2013.

17. Gazmararian JA, Williams MV, Peel J, Baker DW. Health literacy and knowledge of chronic disease. Patient Educ Couns 2003;51:267-275.

18. Chobanian AV, Bakris GL, Black HR, et al. The seventh report of the joint national committee on prevention, detection, evaluation, and treatment of high blood pressure: the JNC 7 report. J Am Med Assoc 2003;289:2560-2571.

19. James PA, Oparil S, Carter BL, et al. 2014 evidence-based guideline for the management of high blood pressure in adults: report from the panel members appointed to the Eighth Joint National Committee (JNC 8). J Am Med Assoc 2014;311:507-520.

20. Rodriguez CJ, Swett K, Agarwal SK, et al. Systolic blood pressure levels among adults with hypertension and incident cardiovascular events: the atherosclerosis risk in communities study. JAMA Intern Med 2014;174:1252-1261.

21. Amine E, Baba N, Belhadj M, et al. Diet, Nutrition and the Prevention of Chronic Diseases: Report of a Joint WHO/FAO Expert Consultation. World Health Organization; 2002.

22. Meyers LS, Gamst G, Guarino A. Applied Multivariate Research: Design and Interpretation. Sage; 2006

23. Viera AJ, Cohen LW, Mitchell CM, Sloane PD. High blood pressure knowledge among primary care patients with known hypertension: a North Carolina Family Medicine Research Network (NC-FM-RN) study. J Am Board Fam Med 2008;21:300-308.

24. Pandit AU, Tang JW, Bailey SC, et al. Education, literacy, and health: mediating effects on hypertension knowledge and control. Patient Educ Couns 2009;75:381-385.

25. Xu LJ, Meng Q, He SW, et al. The effects of health education on patients with hypertension in China: a meta-analysis. Health Educ J 2014;73:137-149.

26. Öztürk A, Aykut M, Günay O, et al. Prevalence and factors affecting of hypertension in adults aged 30 years and over in Kayseri province. Erciyes Tip Derg 2011;33:219-228.

27. Kılıç M. Hypertension prevalence, awareness, and control, and affecting factors among the primary care clients in Yozgat city center. TAF Prev Med Bull 2013;12: 79-86.

28. Göçgeldi E, Babayiğit MA, Hassoy H, Açıkel CH, Taşçı İ. Evaluation of the quality of life perceived by hypertensive patients and of the factors affecting the quality of life. Gülhane Tip Derg 2008;50:172-179. 